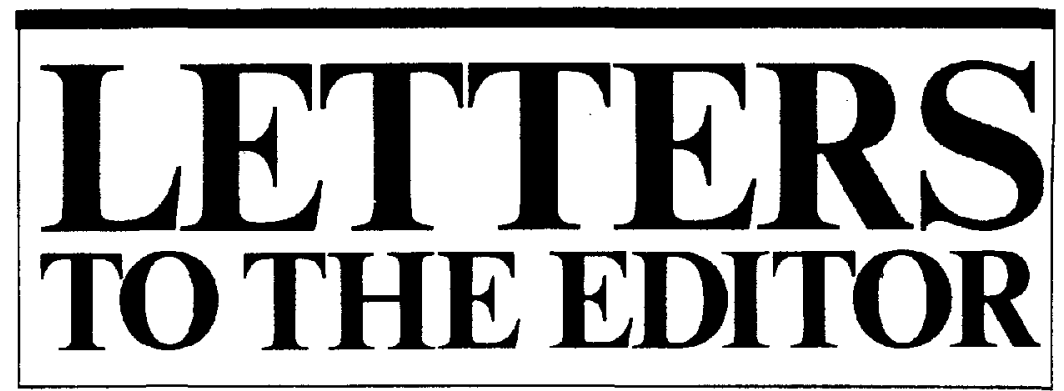

\section{Sweet truth}

Sugar consumption needs to be reduced SIR: John Yudkin has correctly called attention to epidemiologic studies that relate a high intake of sugar with an increased incidence and severity of dental caries (see TIBS, June 1976, p. N 126). Similarly, he calls attention to the statistical relationship between obesity and the amount of sugar consumed annually by a given population. He hastens to emphasize that this does not prove that sugar causes obesity, although many believe this to be the case. Yudkin also calls attention to experimental evidence that large amounts of dietary sugar can increase the blood pressure, as well as the blood lipids of certain species of animals. He does not claim that sucrose per se causes coronary heart disease, although numerous epidemiologic studies do show a significant relationship between the two.

The presentation by Frederick Stare is not worthy of his usual performance. I wonder how many readers can agree with his statement that 15 to $30 \%$ of total calories' supplied by sucrose represents a 'moderate' intake. And later, when he virtually denies any relationship between dietary sugar and dental caries, he is indeed stretching the credibility of the reader. Similarly, his reference to the recommendations for liberalizing the carbohydrate intake of diabetic patients were distorted by his suggestion that sugar can be included among these carbohydrates. The original work upon which this recommendation was based [1] in part, showed clearly that elimination of as much simple sugar as possible and inclusion of complex carbohydrates did result in a reduction in blood lipids without interfering with the level of diabetic control. The same is not true when a substantial portion of the carbohydrate is provided as sugar. And finally, Stare seems to be exceeding the bounds of reason when he asks the reader to accept his argument that sugar causes foods to be consumed, yet does not contribute to obesity. It seems to me that he can't have it both ways'.
I would be the first to agree that the true impact of sugar on the health of people living in the industrialized countries of the world has yet to be fully assessed I firmly believe, however, that it is a major cause of dental caries, and that it is a factor in obesity simply because it leads some people to eat more total calories than they might consume if they avoided sweets. I fully agree that the impact of sugar on blood lipids and on coronary heart disease remains unproven despite several persuasive epidemiologic studies. Meanwhile I shall continue to advise students and patients alike to reduce their consumption of sugar substantially.

KOBERT E. HOUGES Division of Medical Sciences, University of California, Davis, California, U.S.A

\section{Reference}

1 Stone. D.B. and Connor, W.E. (1963) Diabetes $12,127-132$

\section{International survey data}

SIR: According to Fredrick Stare sugar does not cause obesity (see TIBS, June 1976 , p. N 126). My mother, totally ignorant of modern nutrition that she is, knows full well that sugar makes her fat. Anyone knows you cannot eat meat in defiance of the appetite but can easily down sweet tea or coffee after the heaviest meal.

Numerous surveys have shown the close relation between the rise in sugar intake of a population and the epidemic of diabetes and heart disease that always follows. was the cause of massive diabetes amongst In 1963 Campbell demonstrated that sugar
Indians and rural Zulus in South Africa [1] Schaeffer demonstrated how sucrose led to diabetes, atherosclerosis and other ills in the Eskimos [2], while Cohen has shown that a massive rise in sugar intake in Ycmenite Jews in Palestine (Israel) was followed by an equally massive rise in diabetes and heart disease despite a drop in the polyunsaturated/saturated fats ratio [3].

The problem with interpreting international data is that both sugar and saturated fat correlate not only with heart disease but also with each other. Masironi solved this problem by relating the ratio of dietary intake 1962: 1947 with the ratio of deaths from heart disease between 1965 and 1055 for people of all ages in various countries. This broke the link between sucrose and saturated fat. The correlation coefficients were +0.40 for sucrose but -0.27 for saturated fat [4].

Stare finds nothing amiss in a diet containing $15-30 \%$ of calories as sugar. Along with refined cereals this will cause a fall of around $30-70 \%$ in the intake of a dozen or more nutrients. To ignore this is surely the height of folly.

NORMAN TFMPI.E The Polytechnic, Wolverhampton, Staffordshire, U.K

\section{References}

I Campbell, G. D. (1963) S. Afr. Med. 37, 1195-1208

2 Schaeffer, O. (1971) Nutrition Today 6, 8-16

3 Cohen, A. M. (1963) Am. Heart J. 65, 291-293

4 Masironi, R. (1970) Bull. World Health Organ. 42 103-114

\section{South African view}

SIR: Because of the failure of others to confirm his earlier results, Yudkin avers that his opponents consider that this "disposes of the hypothesis that a high intake of sucrose is one of the causes of coronary heart disease (CHD)', and thereby constitutes 'a proof that sucrose is not a cause of the disease (CHD)' (see TIBS, June 1976, p. N 126) Yudkin's contention is inapposite; critics simply regard as unproven the view that sugar is a major and specific aetiological factor.

In South Africa there are four ethnic

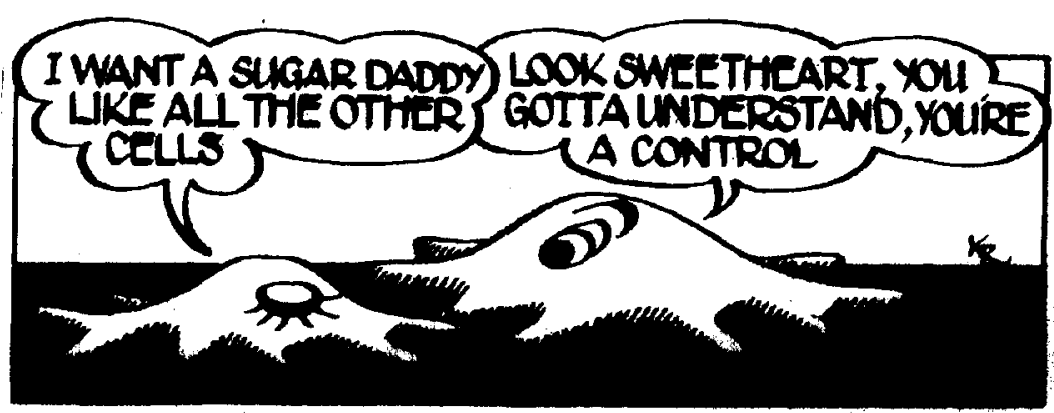

